\title{
Correlation of Skp2 overexpression to prognosis of patients with nasopharyngeal carcinoma from South China
}

\author{
Hui-Min $\mathrm{Xu}^{1,2, \Delta}$, Yi Liang ${ }^{1,3, \Delta}$, Qiong Chen ${ }^{1, \Delta}$, Qi-Nian Wu ${ }^{1,4}$, Yun-Miao Guo ${ }^{1,3}$, Guo-Ping Shen ${ }^{1,2}$, \\ Ru-Hua Zhang ${ }^{1,3}$, Zhi-Wei He ${ }^{5}$, Yi-Xin Zeng ${ }^{1,3}$, Fang-Yun $X_{i e}^{1,2}$, and Tie-Bang Kang ${ }^{1,3}$
}

\section{Abstract}

S-phase kinase-associated protein 2 (Skp2), which plays a role in cell cycle regulation, is commonly overexpressed in a variety of human cancers and associated with poor prognosis. However, its role in nasopharyngeal carcinoma (NPC) is not well understood. In this study, we examined the clinical significance of Skp2, with a particular emphasis on overall survival (OS) and disease-free survival (DFS), in NPC cases in South China, where NPC is an epidemic. Additionally, we explored the function of Skp2 in maintaining a cancer stem cell-like phenotype in NPC cell lines. Skp2 expression was assessed for 127 NPC patients using tissue microarrays and immunohistochemistry and analyzed together with clinicopathologic features, OS, and DFS. Skp2 expression was detectable, or positive, in $75.6 \%$ of patients. Although there was no correlation between Skp2 and any clinicopathologic factor, Skp2 expression significantly portended inferior OS $(P=0.013)$ and DFS $(P=0.012)$. In the multivariate model, Skp2 expression remained significantly predictive of poor OS $[P=0.009$, risk ratio $(\mathrm{RR})=4.06]$ and $\mathrm{DFS}$ $(P=0.008, \mathrm{RR}=3.56)$, and this was also true for clinical stage $(P=0.012$ and $\mathrm{RR}=3.201$ for OS; $P=$ 0.002 and $\mathrm{RR}=1.94$ for DFS $)$ and sex $(P=0.016$ and $\mathrm{RR}=0.31$ for $\mathrm{OS} ; P=0.006$ and $\mathrm{RR}=0.27$ for DFS). After Skp2 knockdown, a colony formation assay was used to evaluate the self-renewal property of stem-like cells in the NPC cell lines CNE-1 and CNE-2. The colony formation efficiency in CNE-1 and CNE-2 cells was decreased. In Skp2-transfected CNE-1 and CNE-2 cells, side population (SP) proportion was increased as detected by flow cytometry. Skp2 is an independent prognostic marker for OS and DFS in NPC. Skp2 may play a role in maintaining the cancer stem cell-like phenotype of NPC cell lines.

Key words S-phase kinase-associated protein 2 (Skp2), nasopharyngeal neoplasm, prognosis, cancer stem cells (CSCs), side population (SP)

S-phase kinase-associated protein 2 (Skp2), a member of the F-box family, is the substrate recognition subunit of the Skp1-Cullin-F box protein (SCF) E3

\footnotetext{
Authors' Affiliations: 'State Key Laboratory of Oncology in South China, Guangzhou, Guangdong 510060, P. R. China; 'Department of Radiation Oncology, Sun Yat-sen University Cancer Center, Guangzhou, Guangdong 510060, P. R. China; ${ }^{3}$ Department of Experimental Research, Sun Yat-sen University Cancer Center, Guangzhou, Guangdong 510060, P. R. China; ${ }^{4}$ Department of Pathology, Sun Yat-sen University Cancer Center, Guangzhou, Guangdong 510060, P. R. China; ${ }^{5}$ Guangdong Medical College Cancer Center, Dongguan, Guangdong 523808, P. R. China. ${ }^{\triangle}$ These authors contributed equally to this work.

Corresponding Authors: Fang-Yun Xie, Tie-Bang Kang, State Key Laboratory of Oncology in South China, Guangzhou, Guangdong 510060, P. R. China; Department of Radiation Oncology, Sun Yat-sen University Cancer Center, Guangzhou, Guangdong 510060, P. R. China; Department of Experimental Research, Sun Yat-sen University Cancer Center, Guangzhou, Guangdong 510060, P. R. China. Tel: +86-20-87343182; Fax: +86-20-87343171; Email: xiefy@ sysucc.org.cn, kangtb@mail.sysu. edu.cn.
}

ubiquitin ligase complex, which mediates ubiquitination of proteins targeted for proteasomal degradation ${ }^{[1]}$. Skp2 recognizes and causes the degradation of some inhibitory proteins, such as p27/Kip1 and p21/Cip1, leading to cell cycle progress. In cancer cells, overexpression of Skp2 results in the dysfunction of cell cycle arrest. If so, cancer cells with DNA damage cannot halt the progress of cell cycle and trigger DNA repair or apoptosis pathways, eventually inducing genomic instability. Therefore, Skp2 is commonly overexpressed and associated with poor prognosis in a variety of human cancers, including colorectal cancer, gastric cancer, breast cancer, and oral cancer ${ }^{[2]}$. Nasopharyngeal carcinoma (NPC), the malignant dysplasia of nasopharyngeal epithelia, is an epidemic malignancy in South China, resulting from the unlimited proliferation of nasopharyngeal epithelia. Due to the essential role of Skp2 in progressing cell cycle, Skp2 level may be associated with NPC development. However, the 
prognostic role of Skp2 in NPC cases from this region has not been investigated.

Current evidence suggests that only a small fraction of cells in a tumor are responsible for its initiation, growth, and development ${ }^{[3]}$, and such cells have been designated cancer stem cells or cancer stem-like cells (CSCs $)^{[4]}$. Most importantly, CSCs usually express membrane transporters like ABCG2 ${ }^{[5]}$ and ABCB5 ${ }^{[6]}$, which can efflux chemotherapeutic agents out of the cell membrane, leading to chemoresistance. CSCs can also acquire the capacities of migration and invasion via epithelial-mesenchymal transition ${ }^{[7,8]}$, therefore resulting in cancer metastasis. In addition, many studies have shown that overexpression of CSC markers, such as ALDH1 in breast cancer ${ }^{[9]}$ and CD133 in colorectal cancer $^{[10]}$, is correlated with poor prognosis. Thus, there is a strong basis for implicating CSCs in tumor development and progression. The side population (SP), a small population of cells distinguished by their ability to efflux the DNA binding dye Hoechst 33342 out of the cell membrane, have been reported to exhibit stem cell characteristics and enrich the stem cell-like population in cancer ${ }^{[5,11,12]}$. Indeed, CSC-like SP cells have been isolated and identified in human NPC cell lines, including CNE-1 and CNE-2 ${ }^{[13]}$. Since our previous study has indicated that genomic instability, possibly initiated by Skp2 overexpression, can induce cancer stem cells ${ }^{[14]}$, we hypothesized that Skp2 may play a potential role in NPC stem cells. In this study, we provided evidence that Skp2 overexpression is associated with poor prognosis of NPC in South China, and this negative relationship is likely due to a Skp2-mediated increase in the SP fraction size.

\section{Materials and Methods}

\section{Patients}

A total of 150 patients who were pathologically diagnosed with NPC and undergone primary treatment at Sun Yat-sen University Cancer Center between October 1999 and December 2000 were recruited. Tissue samples collected from each patient during pretreatment biopsy and clinical follow-up were retrieved from Department of Pathology, Sun Yat-sen University Cancer Center.

\section{NPC tissue microarray and immunohistochemical staining (IHC)}

A tissue microarray of 150 cases was constructed by a pathologist from the Department of Pathology, Sun Yat-sen University Cancer Center. Two tissue cylinders $(1.0 \mathrm{~mm}$ in diameter) were punched from each specimen. For IHC, tissue microarray blocks were cut into slides at $3-\mu \mathrm{m}$ thickness. The slides were deparaffinized in xylene, rehydrated through graded alcohols to water, heated in boiled EDTA buffer ( $\mathrm{pH}$ 8.0) for $10 \mathrm{~min}$, and cooled naturally to room temperature. They were subsequently immersed in 3\% hydrogen peroxide solution for $10 \mathrm{~min}$ to remove endogenous peroxidase activity, blocked with $10 \%$ goat serum at room temperature for $30 \mathrm{~min}$, and then incubated with mouse anti-Skp2 (1:40, Invitrogen) overnight (about 16 h) at $4^{\circ} \mathrm{C}$. After being washed with PBS, the slides were incubated with secondary antibody (Two-step anti-rabbit/mouse universal immunohistochemistry kit, Dako) at room temperature for $30 \mathrm{~min}$ and then developed with $\mathrm{DAB}$ for $6.5 \mathrm{~min}$. Slides were counterstained with hematoxylin. PBS was used to replace the primary antibody as a negative control. The expression of Skp2 was evaluated independently by two pathologists blinded to the clinical and follow-up data. Cells that had brown-yellow granules in the nuclei were defined as positive, whereas cells without brown-yellow granules in the nuclei were defined as negative ${ }^{[15]}$.

\section{Cell culture and siRNA transfection}

NPC cell lines CNE-1 and CNE-2 were obtained from the State Key Laboratory of Oncology in South China. Cells were cultured in DMEM containing $10 \%$ fetal bovine serum at $37^{\circ} \mathrm{C}$ in a humidified atmosphere containing $5 \% \quad \mathrm{CO}_{2}$. Transient transfection of $50 \mathrm{nmol} / \mathrm{L}$ of Skp2 small interfering RNA (siRNA) or scrambled siRNA (negative control) was performed using Lipofectamine RNAiMAX (Invitrogen) according to the manufacturer's instruction. The cells with out siRNA transfection were used as empty control. Both Skp2 siRNA and scrambled siRNA were synthesized by the Ribobio Company (Guangzhou, China). The sequences of the Skp2 siRNA were 5'-GGUAUCGCCUAGCGUCUGAdTdT-3' for sense primer and 5' -UCAGACGCUAGGCGAUACCdTdT-3' for antisense primer. The sequences of scrambled siRNA were 5'-UUCUCCGAACGUGUCACGUTT-3' for sense primer and 5'-ACGUGACACGUUCGGAGAATT-3' for antisense primer.

\section{Western blot assay in NPC cells}

The Western blotting procedure was described previously ${ }^{[14]}$. Briefly, cells were harvested $48 \mathrm{~h}$ after siRNA transfection and lysed in a lysis buffer containing a cocktail of protease inhibitors. After centrifugation at $15000 \times g$ for $15 \mathrm{~min}$ at $4{ }^{\circ} \mathrm{C}$, supernatants were collected, mixed with dithiothreitol and used for the Western blotting. Equal amounts of protein extract were electrophoresed in $10 \%$ SDS-PAGE gels and then transferred to nitrocellulose membranes. The 
membranes were blocked with $3 \%$ non-fat milk at room temperature for $1 \mathrm{~h}$, incubated with anti-Skp2 (1:1000, Invitrogen) overnight at $4{ }^{\circ} \mathrm{C}$, and incubated with the secondary antibody at room temperature for $1 \mathrm{~h}$. After washing the blots with TBST, proteins were visualized by chemiluminescence.

\section{Colony formation assay in NPC cells}

Colony formation assay was performed according to the procedure reported previously ${ }^{[14]}$. Briefly, $36 \mathrm{~h}$ after siRNA transfection, cells were trypsinized, resuspended as single cells, and plated to 6-well plates with 100 cells per well. After 10 days, the colonies were fixed with methanol and stained with crystal violet. Colonies with more than 50 cells were counted under the microscope. The cloning efficiency was calculated by the formula: colony formation rate $=$ (clone number $/$ inoculation cell number) $\times 100 \%$.

\section{Side population detection in NPC cells}

Side population was detected according to the procedure reported previously ${ }^{[14]}$. Briefly, $48 \mathrm{~h}$ after transfection, the cells were harvested and resuspended in DMEM containing $2 \%$ FBS at a concentration of $\sim 1 \times$ $10^{6}$ cells $/ \mathrm{mL}$. Hoechst 33342 (Sigma-Aldrich), a DNA-binding dye, was added at a final concentration of 5 $\mu \mathrm{g} / \mathrm{mL}$, and the suspension was incubated in dark at $37^{\circ} \mathrm{C}$ for $1.5 \mathrm{~h}$ with interval mixing. Another subset of cells were incubated with $50 \mu \mathrm{mol} / \mathrm{L}$ verapamil, which blocked ABCG2 activity to prevent the dye from being pumped out of cell membrane. After exposure to the dye, cells were washed with PBS and kept at $4^{\circ} \mathrm{C}$ before being analyzed with flow cytometry (Moflo XDP, Beckman Coulter). We used dual-wavelength analysis to detect the proportion of SP cells.

\section{Statistical analyses}

Statistical analyses were performed using the SPSS 16.0 software package. The association between clinicopathologic factors and Skp2 expression was evaluated using the Chi-square test. Survival curves were constructed using the Kaplan-Meier method, and Cox regression was used for multivariate analysis. $P$ value $<0.05$ was considered statistically significant.

\section{Results}

\section{Correlation between Skp2 expression and clinicopathologic features of nasopharyngeal carcinoma}

To determine if Skp2 is associated with clinicopathologic features and prognosis of NPC in South China, we used a tissue microarray containing samples from 150 patients with NPC and performed IHC to detect Skp2 expression. Samples from 23 patients dropped off the microarray and 127 could be analyzed. Of the 127 patients, $94(74 \%)$ were men and $33(26 \%)$ were women with a median age of 47 years old (range, 17-73). Among the cases, 4 (3.1\%) were classified as Stage I; $45(35.4 \%)$ as Stage II; $51(40.2 \%)$ as Stage III; and 27 $(21.3 \%)$ as Stage IVa. No patient had distant metastasis. The mean follow-up time was 83 months (range, $11-115$ ), and the 5-year overall survival rate was $74.8 \%$. The clinicopathologic features of these patients are shown in Table 1.

The IHC results showed that the positive rate of Skp2 was $75.6 \%$ in the 127 samples. Brown-yellow granules were observed in the nuclei of cells in positive samples (Figure 1).

No association was found between Skp2 expression and any of the clinicopathologic factors, including sex, age, $\mathrm{T}$ stage, $\mathrm{N}$ stage, clinical stage, pathologic type (WHO), therapy, and the Epstain-Barr virus viral capsid antigen-IgA antibody (EBV VCA-IgA) titer (Table 2).

\section{Prognostic significance of Skp2 expression in NPC}

The correlation between Skp2 expression or clinicopathologic features and prognosis is shown in Table 3. In univariate analysis, Skp2 expression and clinicopathologic factors except age and pathologic type (WHO) could predict the overall survival (OS) or disease-free survival (DFS) (Table 3). In multivariate analysis, Skp2 expression was still significantly predictive for poor OS $[P=0.009$, risk ratio $(\mathrm{RR})=4.06]$ and $\mathrm{DFS}$ $(P=0.008, \mathrm{RR}=3.56)$. In addition, clinical stages $(P=$ 0.012 and $\mathrm{RR}=3.201$ for $\mathrm{OS} ; P=0.002$ and $\mathrm{RR}=1.94$ for DFS) and sex $(P=0.016$ and $\mathrm{RR}=0.31$ for OS; $P=$ 0.006 and $R R=0.27$ for DFS) were also predictive for prognosis of NPC (Table 4). Moreover, the Kaplan-Meier analysis showed that Skp2 expression in the patients with NPC could independently predict poor prognosis for both OS $(P=0.013)$ and DFS $(P=0.012)$ (Figure 2$)$.

\section{Knockdown of Skp2 decreased the colony formation efficiency of NPC cells}

To explore the functional role of Skp2 in cell self-renewal, an important feature of CSCs, we performed a colony formation assay after transient knockdown of Skp2 in CNE-1 and CNE-2 cells. As shown in Figure $3 A$, Skp2 was efficiently knocked down by siRNA in CNE-1 and CNE-2 cells. More importantly, the colony formation efficiency was dramatically decreased in these Skp2-knockdown cells $(P=0.001$ for CNE-1 cells and $P=0.008$ for CNE-2 cells) (Figure 3B), 
Table 1. Clinicopathologic features of 127 patients with nasopharyngeal carcinoma (NPC)

\begin{tabular}{|c|c|c|c|}
\hline Factor & No. of cases (\%) & Factor & No. of cases $(\%)$ \\
\hline Sex & & Clinical stage & \\
\hline Male & $94(74.0)$ & 1 & $4(3.1)$ \\
\hline Female & $33(26.0)$ & ॥ & $45(35.4)$ \\
\hline Age (years) & & III & $51(40.2)$ \\
\hline$<47$ & $62(48.8)$ & IVa & $27(21.3)$ \\
\hline$\geqslant 47$ & $63(49.6)$ & Histological type (WHO) & \\
\hline T stage & & Undifferentiated & $94(74.0)$ \\
\hline $\mathrm{T} 1$ & $10(7.9)$ & Differentiated & $28(22.0)$ \\
\hline $\mathrm{T} 2$ & $56(44.1)$ & Therapy & \\
\hline T3 & $43(33.9)$ & Radiotherapy alone & $107(84.3)$ \\
\hline $\mathrm{T} 4$ & $18(14.2)$ & Chemotherapy alone & $1(0.8)$ \\
\hline N stage & & Radiochemotherapy & $19(15.0)$ \\
\hline NO & $35(27.6)$ & EBV VCA-IgA titer & \\
\hline N1 & $48(37.8)$ & $\leqslant 1 / 160$ & $38(29.9)$ \\
\hline N2 & $34(26.8)$ & $\geqslant 1 / 320$ & $84(66.1)$ \\
\hline \multirow[t]{3}{*}{ N3 } & $10(7.9)$ & Skp2 expression & \\
\hline & & Negative & $31(24.4)$ \\
\hline & & Positive & $96(75.6)$ \\
\hline
\end{tabular}

EBV VCA-IgA, Epstain-Barr virus viral capsid antigen-IgA antibody.
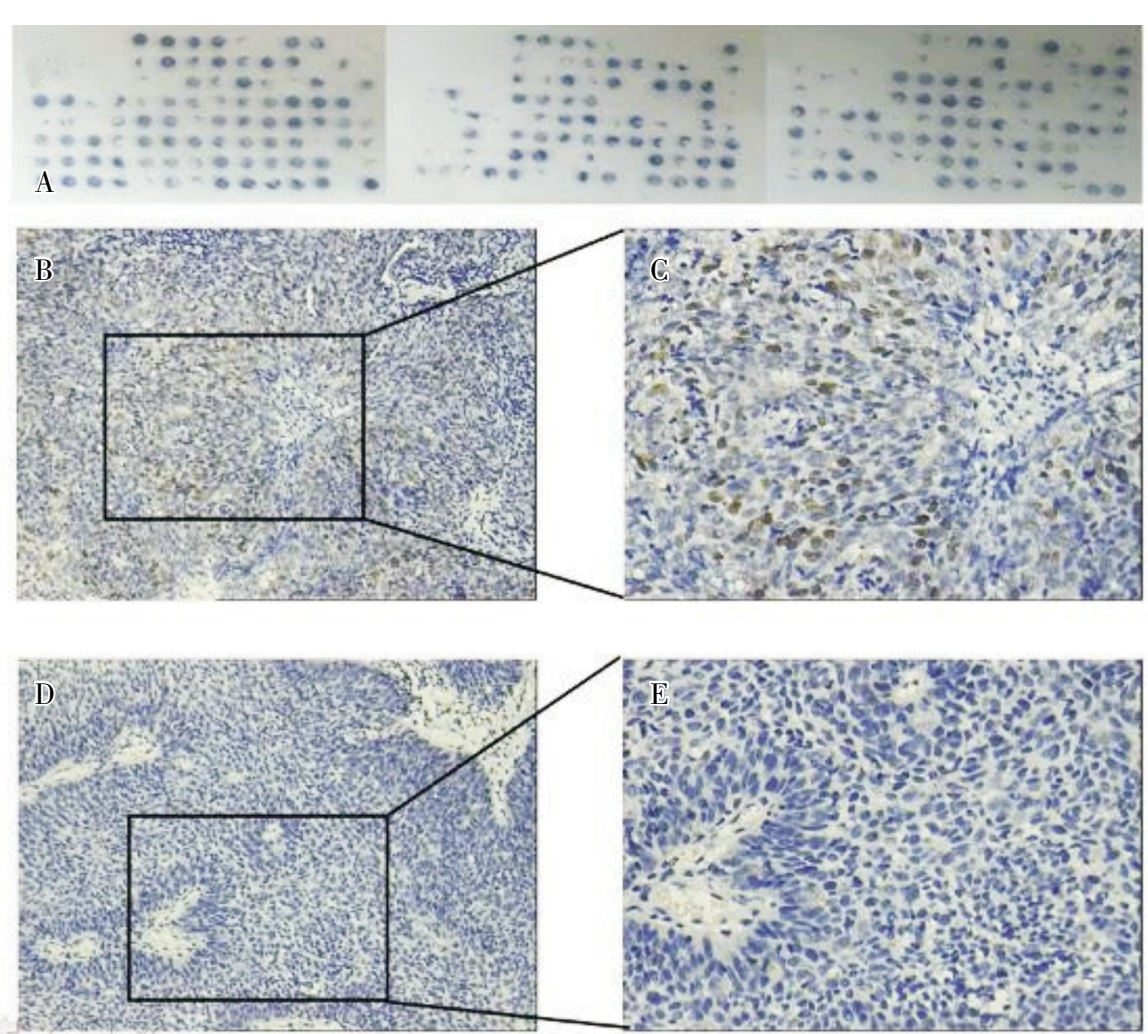

Figure 1. Immunohistochemical staining of Skp2 in tumor samples from 150 patients with nasopharyngeal carcinoma (NPC). A, the NPC tissue microarray shows that 23 samples dropped off the chip and 127 were assessable. B, representative image of a Skp2-positive sample shows that many tumor cells are stained in brown-yellow $(\times 200)$. C, magnification of panel B shows brown-yellow granules in the nuclei of positive tumor cells $(\times 400)$. D, representative image of a Skp2-negative sample shows that no tumor cells are stained in brown-yellow $(\times 200)$. E, magnification of panel $D$ shows no brown-yellow granules in the nuclei of tumor cells $(\times 400)$. 
Table 2. Association between Skp2 expression and clinicopathologic factors of 127 patients with NPC analyzed by the Chi-square test

\begin{tabular}{|c|c|c|c|}
\hline \multirow{2}{*}{ Clinicopathologic factor } & \multicolumn{2}{|c|}{ Skp2 expression } & \multirow{2}{*}{$P$ value } \\
\hline & Positive & Negative & \\
\hline Sex & & & 0.15 \\
\hline Male & 68 & 26 & \\
\hline Female & 28 & 5 & \\
\hline Age (Years) & & & 0.133 \\
\hline$<47$ & 43 & 19 & \\
\hline$\geqslant 47$ & 51 & 12 & \\
\hline $\mathrm{T}$ stage & & & 0.15 \\
\hline $\mathrm{T} 1$ & 5 & 5 & \\
\hline $\mathrm{T} 2$ & 42 & 14 & \\
\hline T3 & 33 & 10 & \\
\hline $\mathrm{T} 4$ & 16 & 2 & \\
\hline $\mathrm{N}$ stage & & & 0.109 \\
\hline NO & 27 & 8 & \\
\hline N1 & 31 & 17 & \\
\hline N2 & 29 & 5 & \\
\hline N3 & 9 & 1 & \\
\hline Clinical stage & & & 0.197 \\
\hline $1+\|$ & 34 & 15 & \\
\hline$I I I+I V a$ & 62 & 16 & \\
\hline Histological type (WHO) & & & 0.149 \\
\hline Undifferentiated & 68 & 26 & \\
\hline Differentiated & 24 & 4 & \\
\hline Therapy & & & 0.712 \\
\hline Radiotherapy/chemotherapy & 81 & 27 & \\
\hline Radiochemotherapy & 15 & 4 & \\
\hline EBV VCA-IgA titer & & & 0.542 \\
\hline$\leqslant 1 / 160$ & 30 & 8 & \\
\hline$\geqslant 1 / 320$ & 62 & 22 & \\
\hline
\end{tabular}
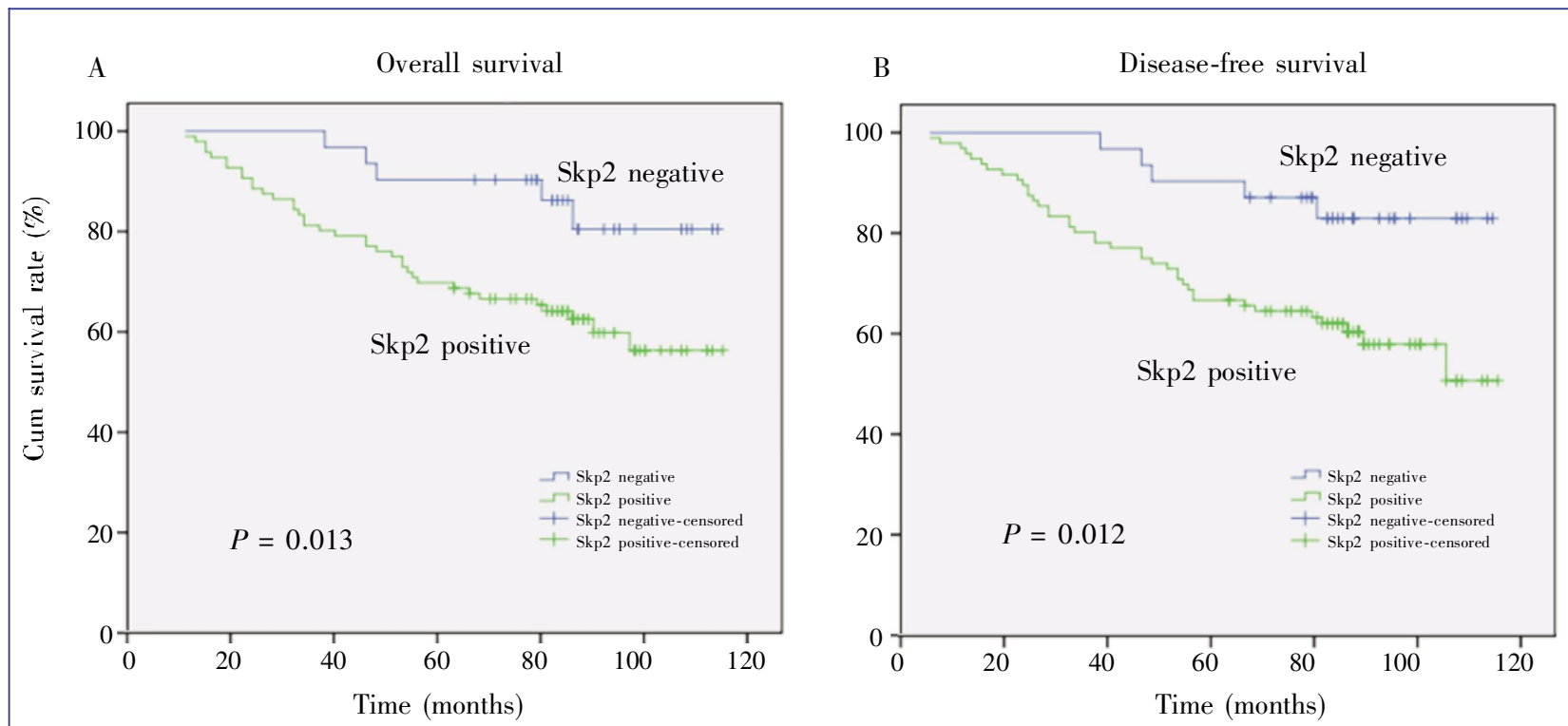

Figure 2. Kaplan-Meier survival curves of 96 Skp2-positive and 31 Skp2-negative patients with NPC. Skp2 expression is associated with poor overall survival $(A, P=0.013)$ and disease-free survival $(B, P=0.012)$ of patients with NPC. 
Table 3. Results of univariate log-rank analysis of prognostic factors of 127 patients with NPC

\begin{tabular}{|c|c|c|c|c|c|}
\hline \multirow{2}{*}{ Variate } & \multirow{2}{*}{ No. of patients } & \multicolumn{2}{|c|}{ OS } & \multicolumn{2}{|c|}{ DFS } \\
\hline & & Events $^{\mathrm{a}}$ & $P$ value & Events $^{b}$ & $P$ value \\
\hline Sex & & & 0.028 & & 0.013 \\
\hline Male & 94 & 35 & & 39 & \\
\hline Female & 33 & 5 & & 5 & \\
\hline Age (years) & & & 0.046 & & 0.115 \\
\hline$<47$ & 62 & 14 & & 17 & \\
\hline$\geqslant 47$ & 63 & 26 & & 27 & \\
\hline T stage & & & 0.002 & & $<0.001$ \\
\hline $\mathrm{T} 1$ & 10 & 2 & & 2 & \\
\hline T2 & 56 & 11 & & 13 & \\
\hline T3 & 43 & 16 & & 17 & \\
\hline $\mathrm{T} 4$ & 18 & 11 & & 12 & \\
\hline N stage & & & 0.016 & & 0.003 \\
\hline NO & 35 & 6 & & 7 & \\
\hline N1 & 48 & 14 & & 16 & \\
\hline N2 & 34 & 14 & & 15 & \\
\hline N3 & 10 & 6 & & 6 & \\
\hline Clinical stage & & & $<0.001$ & & $<0.001$ \\
\hline 1 & 4 & 1 & & 1 & \\
\hline$\|$ & 45 & 6 & & 8 & \\
\hline III & 51 & 17 & & 18 & \\
\hline IVa & 27 & 16 & & 17 & \\
\hline Histological type (WHO) & & & 0.175 & & 0.349 \\
\hline Undifferentiated & 94 & 28 & & 32 & \\
\hline Differentiated & 28 & 12 & & 12 & \\
\hline Therapy & & & 0.014 & & 0.008 \\
\hline Radiotherapy/chemotherapy & 108 & 30 & & 33 & \\
\hline Radiochemotherapy & 19 & 10 & & 11 & \\
\hline EBV VCA-IgA & & & 0.027 & & 0.072 \\
\hline$\leqslant 1 / 160$ & 38 & 7 & & 9 & \\
\hline$\geqslant 1 / 320$ & 84 & 33 & & 34 & \\
\hline Skp2 expression & & & 0.02 & & 0.018 \\
\hline Negative & 31 & 4 & & 5 & \\
\hline Positive & 96 & 36 & & 39 & \\
\hline
\end{tabular}

OS, overall survival; DFS, disease-free survival. ${ }^{a}$ Events in OS include death; ${ }^{b}$ events in DFS include local or region relapse or distant metastasis.

suggesting that Skp2 may play a key role in the self-renewal of NPC cells.

\section{Overexpression of Skp2 increased the percentage of SP cells}

We investigated whether Skp2 could affect the percentage of SP cells using CNE-1 and CNE-2 cells. Consistent with the result of colony formation assay, overexpression of Skp2 increased the percentage of SP cells in both CNE-1 and CNE-2 cells (Figure 4), indicating that Skp2 may be involved in the production of CSCs in NPC.

\section{Discussion}

In the present report, we show that Skp2 was highly expressed in tumor samples from the patients with NPC in South China; moreover, expression of Skp2 was an independent indicator of poor prognosis for NPC $(P=$ 0.013 for OS and $P=0.012$ for DFS). Fang et al. ${ }^{[16]}$ studied NPC cases in Taiwan, another epidemic region of NPC, found that Skp2 overexpression was associated with OS and distant metastasis-free survival but not with the locoregional control. Taken together, these results suggest that Skp2 may be useful for predicting prognosis of NPC.

CSCs are a subpopulation of cancer cells that harbor stem cell characteristics like self-renewal and differentiation. CSCs have strong ability of chemoresistance ${ }^{[17]}$. They usually express cell membrane transporters like $A B C G 2$ and $A B C B 1$, which can efflux chemotherapy compounds out of cells. Furthermore, because of their capability of mobility and invasion, it is 
Table 4. Results of multivariate Cox regression analysis of prognostic factors of 127 patients with NPC

\begin{tabular}{llllll}
\hline \multirow{2}{*}{ Variate } & \multicolumn{2}{c}{ OS } & & \multicolumn{2}{c}{ DFS } \\
\cline { 2 - 3 } \cline { 5 - 6 } & RR $(95 \% \mathrm{Cl})$ & $P$ value & & RR $(95 \% \mathrm{Cl})$ & $P$ value \\
\hline Skp2 expression (positive) & $4.063(1.422-11.610)$ & 0.009 & & $3.560(1.385-9.153)$ & 0.008 \\
Clinical stage (III+IV) & $3.201(1.296-7.906)$ & 0.012 & & $1.940(1.275-2.952)$ & 0.002 \\
Sex (female) & $0.310(0.120-0.801)$ & 0.016 & & $0.270(0.106-0.690)$ & 0.006 \\
Age ( $\geqslant 47)$ & - & 0.073 & & - & - \\
Therapy (radiochemotherapy) & - & 0.404 & & - & 0.295 \\
VCA-IgA ( $\geqslant 1 / 320)$ & - & 0.360 & & - & - \\
\hline
\end{tabular}

RR, risk ratio; $95 \% \mathrm{Cl}, 95 \%$ confidence interval. "-" indicates that the risk ratio was not calculated because $P$ value $>0.05$.

A

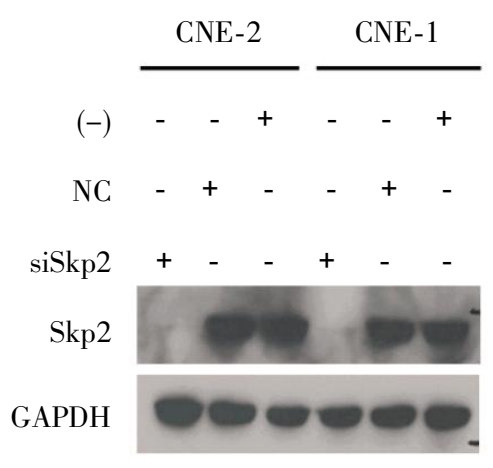

B

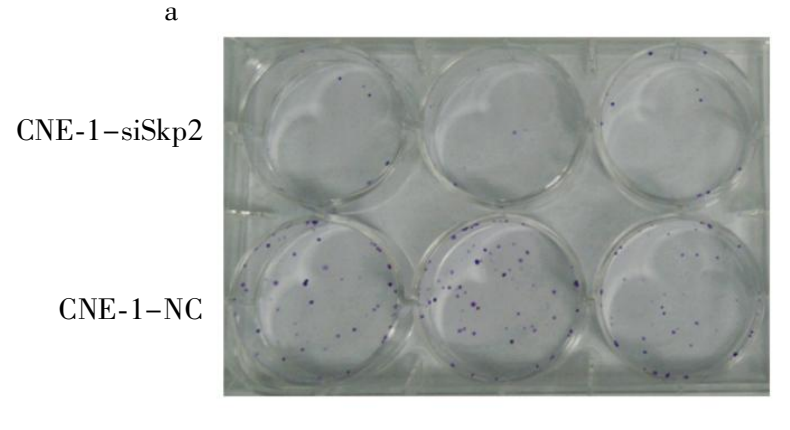

c

CNE-2-siSkp2

CNE-2-NC

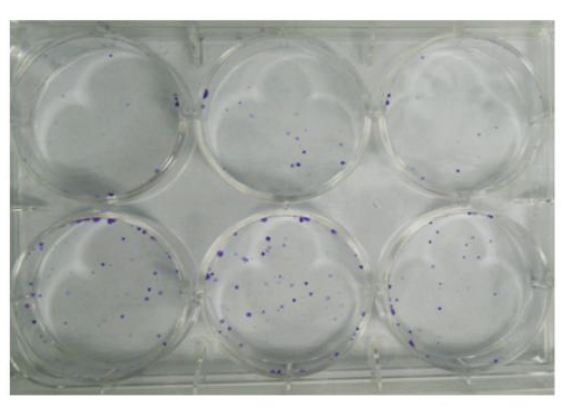

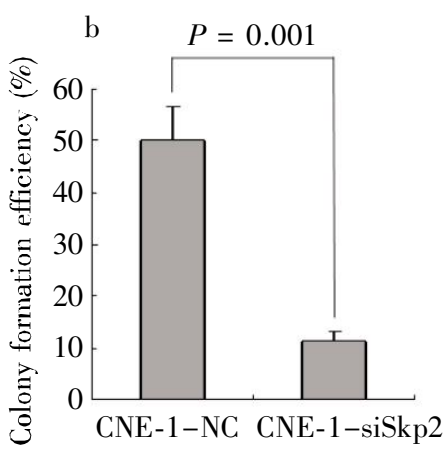

d

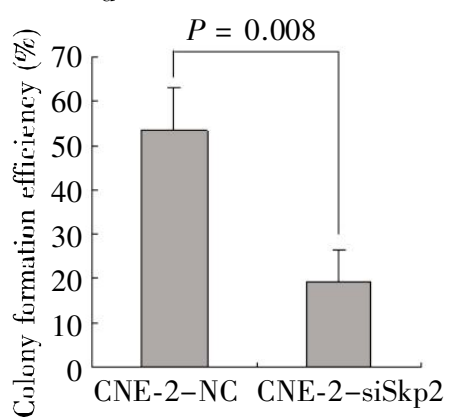

Figure 3. Knockdown of Skp2 significantly decreases the colony formation efficiency in human NPC cells. CNE-1 and CNE-2 cells were transfected with Skp2 siRNA (siSkp2) or scrambled siRNA (NC) for $48 \mathrm{~h}$. A, Western blotting shows no Skp2 expression in Skp2 siRNA-transfected cells, and no changes of Skp2 expression in scrambled siRNA-transfected cells and untransfected cells. B, the colony formation assay shows that the number of colonies is significantly lower in Skp2 siRNA-transfected cells than in scrambled siRNA-transfected cells $(P<0.01)$. 


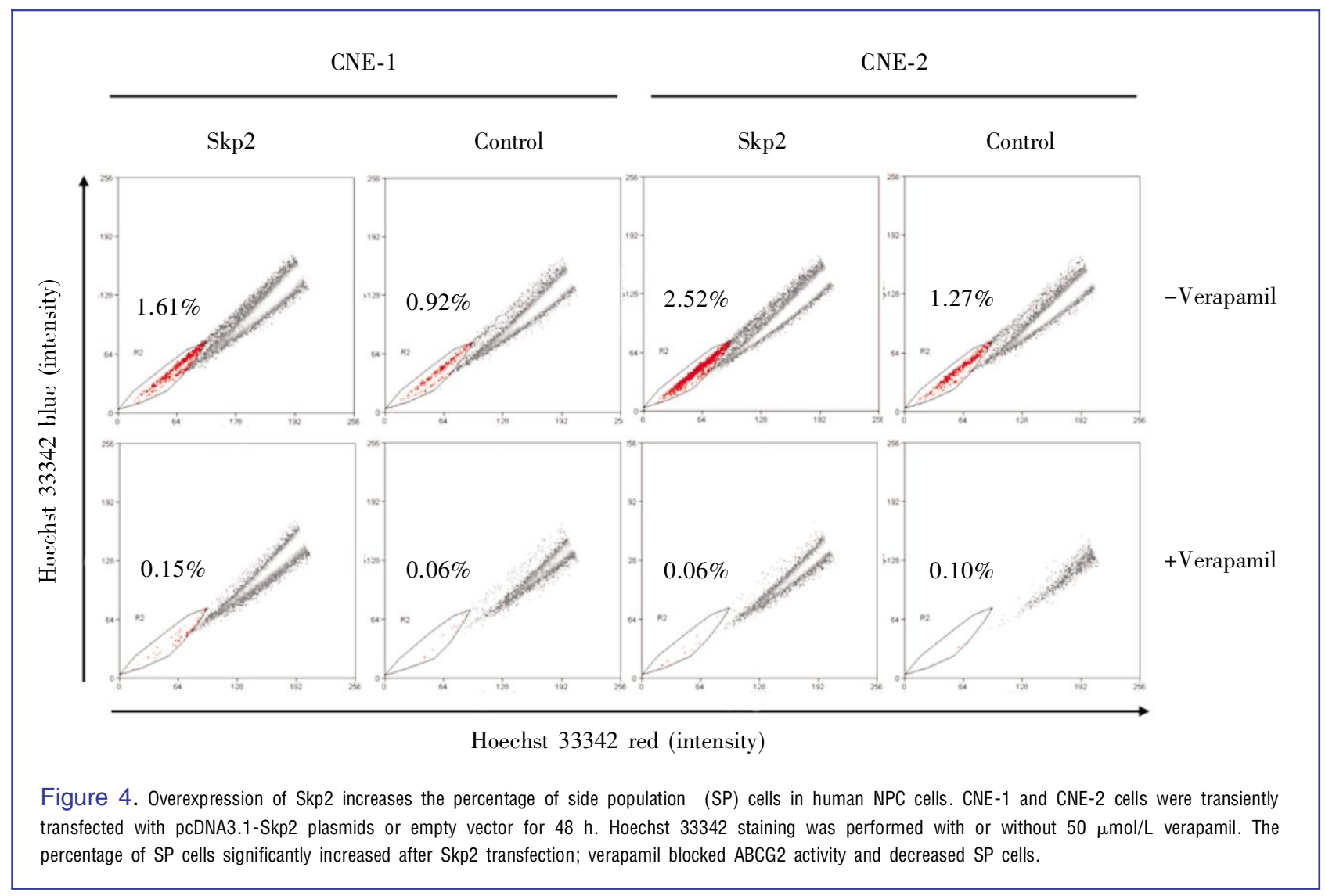

currently accepted that CSCs are responsible for metastasis ${ }^{[8,17]}$, leading to a possible correlation between CSC-like phenotype and prognosis of cancer. SP is a distinct subpopulation that has properties of stem cells and can efflux the DNA-binding dye Hoechst 33342 out of the cell membrane ${ }^{[5,11,12]}$. Previously, we determined that SP cells existed in five NPC cell lines including CNE-1 and CNE-2 (0.7\% for CNE-1 and $2.6 \%$ for CNE-2), and these SP cells, like CSCs, had the ability to self-renew, proliferate, differentiate, and initiate tumorigenesis in vivo[13]. Our results using NPC cell lines show that Skp2 knockdown dramatically decreased colony formation efficiency, whereas Skp2 overexpression increased the fraction of SP cells, indicating that Skp2 may play an important role in the production or maintenance of CSCs in NPC. Furthermore, Skp2 may influence the prognosis of NPC partially by increasing the proportion of CSCs among NPC cells. This may explain our results and the results of Fang et al. ${ }^{[16]}$, which show that Skp2 is associated with poor clinical outcome of NPC in South China and Taiwan, respectively.

Genomic instability triggered by deficiencies in DNA repair and apoptosis is a well-known hallmark of cancer. Skp2, an important regulator of the cell cycle, is often overexpressed in cancers. In principle, dysfunction of
Skp2 may cause cell cycle abnormalities, which, in turn, increase the genomic instability of cancer cells. We recently reported that genomic instability could induce CSC production in cancer cells ${ }^{[14]}$. Thus, these observations provide one possible explanation for the correlation between Skp2 expression and CSC-like phenotype in NPC cells, as indicated by colony formation assay and SP cell detection assay. However, further investigation is needed to establish the key role of Skp2 in CSCs or in the development of NPC.

\section{Acknowledgments}

We thank Department of Pathology, Sun Yet-sen University Cancer Center for the assistance in NPC tissue microarray. This work was supported by National Natural Science Foundation of China (No. u0732005, No. 30930045); Major State Basic Research Development Program of China (No. 2010CB912201); National High Technology Research and Development Program of China (No. 2006AA02A404); and Sun Yat-sen University 985 Program.

Received: 2010-08-16; revised: 2010-11-28; accepted: 2010-12-30. 


\section{References}

[1] Ji P, Goldin L, Ren H, et al. Skp2 contains a novel cyclin a binding domain that directly protects cyclin a from inhibition by p27kip1 [J]. J Biol Chem, 2006,281(33):24058-24069.

[2] Hershko DD. Oncogenic properties and prognostic implications of the ubiquitin ligase skp2 in cancer [J]. Cancer, 2008,112(7): $1415-1424$.

[3] Reya T, Morrison SJ, Clarke MF, et al. Stem cells, cancer, and cancer stem cells [J]. Nature, 2001,414(6859): 105-111.

[4] Houghton J, Morozov A, Smirnova I, et al. Stem cells and cancer [J]. Semin Cancer Biol, 2007,17(3):191-203.

[5] Zhou S, Schuetz JD, Bunting KD, et al. The abc transporter bcrp1/abcg2 is expressed in a wide variety of stem cells and is a molecular determinant of the side-population phenotype [J]. Nat Med, 2001,7(9):1028-1034

[6] Schatton T, Murphy GF, Frank NY, et al. Identification of cells initiating human melanomas [J]. Nature, 2008,451(7176):345349

[7] Mani SA, Guo W, Liao MJ, et al. The epithelial-mesenchymal transition generates cells with properties of stem cells [J]. Cell, 2008,133(4):704-715

[8] Pang R, Law WL, Chu AC, et al. A subpopulation of CD26 + cancer stem cells with metastatic capacity in human colorectal cancer [J]. Cell Stem Cell, 2010,6(6):603-615

[9] Ginestier C, Hur MH, Charafe-Jauffret E, et al. Aldh1 is a marker of normal and malignant human mammary stem cells and a predictor of poor clinical outcome [J]. Cell Stem Cell, 2007,1(5):555-567.
[10] Li CY, Li BX, Liang Y, et al. Higher percentage of CD133+ cells is associated with poor prognosis in colon carcinoma patients with stage IIIb [J]. J TransI Med, 2009, 7:56

[11] Hirschmann-Jax C, Foster AE, Wulf GG, et al. A distinct "Side population" Of cells with high drug efflux capacity in human tumor cells [J]. Proc Natl Acad Sci U S A, 2004,101(39): $14228-14233$.

[12] Haraguchi $N$, Utsunomiya $\mathrm{T}$, Inoue $\mathrm{H}$, et al. Characterization of a side population of cancer cells from human gastrointestinal system [J]. Stem Cells, 2006,24(3):506-513.

[13] Wang J, Guo LP, Chen LZ, et al. Identification of cancer stem cell-like side population cells in human nasopharyngeal carcinoma cell line [J]. Cancer Res, 2007,67(8):3716-3724.

[14] Liang $Y$, Zhong $Z$, Huang $Y$, et al. Stem-like cancer cells are inducible by increasing genomic instability in cancer cells [J]. J Biol Chem, 2010,285(7):4931-4940.

[15] Lee SH, Lee JK, Jin SM, et al. Expression of cell-cycle regulators (cyclin d1, cyclin e, p27kip1, p57kip2) in papillary thyroid carcinoma [J]. Otolaryngol Head Neck Surg, 2010,142 (3):332-337.

[16] Fang FM, Chien CY, Li CF, et al. Effect of S-phase kinaseassociated protein 2 expression on distant metastasis and survival in nasopharyngeal carcinoma patients [J]. Int $\mathrm{J}$ Radiat Oncol Biol Phys, 2009,73(1):202-207.

[17] Gupta PB, Onder TT, Jiang G, et al. Identification of selective inhibitors of cancer stem cells by high-throughput screening [J]. Cell, 2009,138(4):645-659.
Submit your next manuscript to Chinese Journal of Cancer and take full advantage of:

- Open access

- No charge to authors

- Quickly published

- Thorough peer review

- Professionally edited

- No space constraints

- Indexed by PubMed, CA, and Google Scholar

Submit your manuscript at www.cjcsysu.com 